\title{
Assessing the reliability of peatland GPP measurements by remote sensing: from plot to landscape scale
}

Article

Accepted Version

Creative Commons: Attribution-Noncommercial-No Derivative Works 4.0

Lees, K. J., Khomik, M., Quaife, T. ORCID:

https://orcid.org/0000-0001-6896-4613, Clark, J. M. ORCID: https://orcid.org/0000-0002-0412-8824, Hill, T., Klein, D., Ritson, J. and Artz, R. R. E. (2021) Assessing the reliability of peatland GPP measurements by remote sensing: from plot to landscape scale. Science of the Total Environment, 766. 142613. ISSN 0048-9697 doi:

https://doi.org/10.1016/j.scitotenv.2020.142613 Available at https://centaur.reading.ac.uk/93388/

It is advisable to refer to the publisher's version if you intend to cite from the work. See Guidance on citing.

To link to this article DOI: http://dx.doi.org/10.1016/j.scitotenv.2020.142613

Publisher: Elsevier

All outputs in CentAUR are protected by Intellectual Property Rights law, including copyright law. Copyright and IPR is retained by the creators or other copyright holders. Terms and conditions for use of this material are defined in the End User Agreement. 


\section{www.reading.ac.uk/centaur}

\section{CentAUR}

Central Archive at the University of Reading

Reading's research outputs online 


\title{
1 Assessing the reliability of peatland GPP measurements by remote sensing: from plot to landscape scale.
}

\author{
3 Kirsten J Lees ${ }^{1,2 *}$, Myroslava Khomik ${ }^{3}$, Tristan Quaife ${ }^{4}$, Joanna M Clark ${ }^{1}$, Tim Hill ${ }^{2}$, \\ Daniela Klein $^{5}$, Jonathan Ritson ${ }^{6}$, and Rebekka RE Artz \\ 1. Department of Geography and Environmental Science, University of Reading, Whiteknights, RG6 6DW, \\ UK. \\ 2. Department of Geography, University of Exeter, Streatham Campus, Exeter, EX4 4QE, UK \\ 3. University of Waterloo, ON N2L 3G1, Canada \\ 4. National Centre for Earth Observation, Department of Meteorology, University of Reading, Reading, \\ Whiteknights, RG6 6BB, UK. \\ 5. Forsinard Flows RSPB Office, Forsinard, KW13 6YT, UK \\ 6. Imperial College London, SW7 2A7 UK \\ 7. The James Hutton Institute, Craigiebuckler, Aberdeen, AB15 8QH, UK
}

\begin{abstract}
Estimates of peatland carbon fluxes based on remote sensing data are a useful addition to monitoring methods in these remote and precious ecosystems, but there are questions as to whether large-scale estimates are reliable given the small-scale heterogeneity of many peatlands. Our objective was to consider the reliability of models based on Earth Observations for estimating ecosystem photosynthesis at different scales using the Forsinard Flows RSPB reserve in Northern Scotland as our study site. Three sites across the reserve were monitored during the growing season of 2017. One site is near-natural blanket bog, and the other two are at different stages of the restoration process after removal of commercial conifer forestry. At each site we measured small (flux chamber) and landscape scale (eddy covariance) $\mathrm{CO}_{2}$ fluxes, small scale spectral data using a handheld spectrometer, and obtained corresponding satellite data from MODIS. The variables influencing GPP at small scale, including microforms and dominant vegetation species, were assessed using exploratory factor analysis. A GPP model using land surface temperature and a measure of greenness from remote sensing data was tested and compared to chamber and eddy covariance $\mathrm{CO}_{2}$ fluxes; this model returned good results at all scales (Pearson's correlations of 0.57 to 0.71 at small scale, 0.76 to 0.86 at large scale). We found that the effect of microtopography on GPP fluxes at the study sites was spatially and temporally inconsistent, although connected to water content and vegetation species. The GPP fluxes measured using EC were larger than those using chambers at all sites, and the reliability of the TG model at different scales was dependent on the measurement methods used for calibration and validation. This suggests that GPP measurements from remote sensing are robust at all scales, but that the methods used for calibration and validation will impact accuracy.
\end{abstract}

Keywords: TG model, photosynthesis, NDVI, satellite, blanket bog

*Corresponding author: K.lees@exeter.ac.uk

1 Introduction

Peatlands are important ecosystems for carbon sequestration, but many areas in the Northern

Hemisphere have experienced degradation through human land use. As an organic-rich, watersaturated substrate, peat stores huge amounts of carbon relative to the land area it occupies due to inhibited decomposition. In Scotland, peatlands store $56 \%$ of total soil carbon whilst occupying $24 \%$ of the land area (Chapman et al., 2009). Many peatland areas have, however, 
forestry, which have reduced saturation and increased bulk density of the peat (JNCC, 2011). Restoration of peatland areas is of interest to policy makers as a carbon emissions abatement scheme (IUCN, 2016; European Commission, 2018), but needs to be based on a robust understanding of peatland ecosystems in order to effectively reverse previous damage. Practitioners need techniques to assess changes in peatland carbon fluxes at a landscape scale in order to measure the success of restoration processes and detect where to focus further efforts.

Upscaling of ecosystem processes is an important research area in ecology, as landscape and regional scale estimates are needed for policy decisions and carbon accounting (Fu et al., 2014; Le Clec'h et al., 2018). Blanket bogs (peatland covering large areas and sustained by rainfall and relatively low annual temperature fluctuations (Lindsay, 2010)) in particular have smallscale heterogeneity in topographic features known as hummocks and hollows, which can vary at scales of less than a metre (Belyea and Clymo, 2001). This microtopographical variation influences vegetation communities, which can induce significant variation in carbon fluxes (Dinsmore et al., 2009; Arroyo-Mora et al., 2018; Peichl et al., 2018).

Conventional methods of carbon dioxide $\left(\mathrm{CO}_{2}\right)$ exchange measurement include flux chambers and Eddy Covariance (EC) towers, both of which cover relatively small areas and are expensive to manage and maintain. Remote sensing has the potential to help monitor carbon fluxes in these important, remote and extensive areas that are difficult to access for conventional fieldbased measurements as well as sensitive to trampling, yet little testing of methods has been carried out (Lees et al., 2018). The existence of satellites with very fine spatial resolution (to tens of metres in freely accessible data) means that studies can now consider variation within a landscape, but the microtopography of blanket bogs is still at a scale that is too fine to be detectable from non-commercial satellite data (Becker et al., 2008). Models using satellite data to estimate carbon fluxes are being developed to cover large areas (Lees et al., 2018) and have 
recently shown successes in estimating carbon fluxes from peatland landscapes (Kross, Seaquist and Roulet, 2016; Lees, Quaife, et al., 2019), but there is still uncertainty over whether these models can adequately detect the variation from small-scale peatland heterogeneity (Zhang et al., 2007; Arroyo-Mora et al., 2018). The focus of this study is therefore to assess whether the small-scale variations in carbon fluxes due to microtopography can be detected using remote sensing data, and whether large scale estimates using these techniques are a reliable estimate of the average fluxes resulting from these mosaic landscapes.

A Temperature and Greenness (TG) model is specifically considered in this study, as this has previously been shown to give good agreement with EC data over the same study area as used in this work (Lees, Quaife, et al., 2019). This model combines a measure of land surface temperature with a vegetation index, in this case the Normalised Difference Vegetation Index (NDVI), to give an estimate of Gross Primary Productivity (GPP).

The aim of this work is to consider what factors affect GPP in blanket bog, and whether the results from large scale models using satellite data can give reliable estimates of photosynthesis measurements made at smaller scales. We hypothesise that the TG model will give good agreement with chamber flux data at the small scale, and with EC data at the larger scale. We also expect that the measurements and estimates at different spatial scales will show similar results in both patterns and values. The approaches are tested at the Forsinard Flows RSPB (Royal Society for the Protection of Birds) reserve, which is an ideal study location as it has a chronosequence of areas undergoing restoration from commercial forestry (Hancock et al., 2018), and long-term Eddy Covariance (EC) monitoring of greenhouse gas emissions (Hambley et al., 2019) at several of the restoration sites.

\section{Methods}

\subsection{Field sites}


94 This research is based at three field sites within the Forsinard Flows RSPB reserve in Northern 95 Scotland (approx. 58.36, -4.04 to 58.43, -3.63, WGS84). The reserve is part of the much larger blanket bog Flow Country EU Natura site. Cross Lochs is a near natural site (see Levy and

97 Gray, (2015), where no drainage has been applied. An EC tower is located at 58.3703,-3.9644 98 (WGS84), elevation $211 \mathrm{~m}$.

99 Talaheel and Lonielist are both sites undergoing restoration, which were previously drained 100 and subsequently planted for commercial conifer (sitka spruce Picea sitchensis and lodgepole 101 pine Pinus contorta) forestry in the mid to late 1980s.

102 Talaheel was initially felled in 1998, with the trees laid into the planting furrows; some areas 103 have since undergone partial further landscaping (which affects half the points in this study) to 104 crush the decomposing conifer brash and to create peat dams in the furrows (winter 2015/16). 105 This has led to raised water levels across the site (see Hancock et al., 2018). The EC tower is 106 located at 58.4146, -3.8006 (WGS84), elevation $196 \mathrm{~m}$.

107 The conifer plantation at Lonielist was felled in winter 2003/2004. At the time of measurement, 108 it retained the distinctive pattern of ridges on which the trees were planted, and drainage ditches 109 infilled with the felled trees. This site had undergone no further management until the end of 110 this project (-end of 2017). The EC tower is located at 58.3910, -3.7651 (WGS84), elevation $111180 \mathrm{~m}$.

112 All three sites are subject to some light grazing by wild red deer (Cervus elephantus). Talaheel

113 is fenced as part of a larger enclosure including some forestry, although some deer are present 114 inside the fence, whilst Lonielist and Cross Lochs are entirely open to grazing.

115 Small scale measurement points were set up in the area within each site's EC tower footprint.

116 The precise distances from the tower and dominant wind directions (Northwest and Southwest) were determined from Hambley (2016) to incorporate appropriate locations within the average 
118 flux tower footprints. At each site two perpendicular crossing transects were set up, one

119 including five points and extending away from the tower into the dominant wind direction, and

120 one including four points and extending into the secondary wind direction (see Figure 1). At

121 Lonielist the main transect was $80 \mathrm{~m}$ and the secondary transect was $60 \mathrm{~m}$, with all points 20

$122 \mathrm{~m}$ apart. At Talaheel the transects were $100 \mathrm{~m}$ and $75 \mathrm{~m}$ with the points $25 \mathrm{~m}$ apart, and at

123 Cross Lochs the transects were $120 \mathrm{~m}$ and $90 \mathrm{~m}$ with points $30 \mathrm{~m}$ apart. At each point two PVC

124 collars (24 cm in diameter) were placed: one on higher microforms (ridges in the restored sites,

125 hummocks at Cross Lochs) and one on lower microforms (in the furrows at the restored sites,

126 hollows at Cross Lochs); therefore, there were 16 collars at each of the three sites. The collars

127 were $8 \mathrm{~cm}$ depth and were inserted to approximately $4 \mathrm{~cm}$ below ground. At least 24 hours

128 were allowed between collar insertion and first measurements.

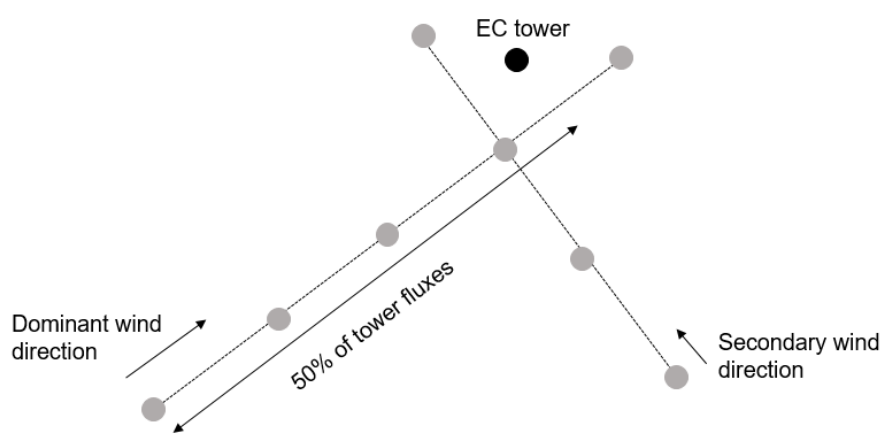

Figure 1 - Location of points within the tower footprint. Two collars, one on a higher microform and one in a lower area, were placed at each point.

\subsection{Chamber flux measurements}

134 Monthly in situ $\mathrm{CO}_{2}$ flux measurements beginning March and ending September 2017 were

135 taken using a LICOR-8100A (LICOR Inc., Lincoln, Nebraska, USA) portable infrared gas analyser and custom Perspex chambers of $24 \mathrm{~cm}$ diameter and $30 \mathrm{~cm}$ height. Small 9V battery-

137 operated fans were installed within the chambers to circulate the air. The two chambers, one

138 clear and one covered with a blackout cloth, were sealed to the collars using rubber mastic 
139 (Terostat), and consecutive measurements were taken with a brief aeration period as the

140 chambers were exchanged. Each measurement period was five minutes, with a 20 second pre-

141 measurement stabilisation period. Chamber flux measurements were usually taken between 8

142 am and $2 \mathrm{pm}$, although this was sometimes altered due to weather conditions. Each collar was

143 measured once with a clear-chamber and once with a blackout chamber on each visit except

144 when adverse weather conditions prevented a full dataset being collected.

$145 \quad$ 2.3. Field spectrometry

146 Spectral measurements in the field were taken on the same visits as the chamber flux data

147 collection using a handheld SVC HR-1024 (Spectra Vista Corporation, spectral resolution 3.5

148 to $9.5 \mathrm{~nm}$ ) spectroradiometer mounted on a monopod and held approximately $1 \mathrm{~m}$ from the

149 surface using an $8^{\circ} \mathrm{FOV}$ lens with an on-the-ground footprint within the diameter of the collars.

150 The spectral range of the instrument is from $337 \mathrm{~nm}$ to $2521 \mathrm{~nm}$. Three measurements were

151 taken of the vegetation within each collar, at three different angles to minimise structural effects

152 (opposite the position of the sun and at $90^{\circ}$ to either side). A Spectralon reference panel was

153 also measured before each observation (within a minute) to normalise from radiance to

154 reflectance.

155 The Normalised Difference Vegetation Index (NDVI) is calculated from the difference 156 between reflectance in red wavelengths of light, which plants absorb strongly, and the near-

157 infrared (NIR), which plants reflect:

$158 \quad \mathrm{NDVI}=\left(\mathrm{R}_{\mathrm{NIR}}-\mathrm{R}_{\text {red }}\right) /\left(\mathrm{R}_{\mathrm{NIR}}+\mathrm{R}_{\mathrm{red}}\right)$

159 In this study we calculated the red and NIR bands as the average of the values in wavelengths

$160 \quad 630-680 \mathrm{~nm}$ and $845-885 \mathrm{~nm}$ respectively. 
162 Photosynthetically Active Radiation (PAR) was measured outside the chamber during clear

163 chamber measurements. Soil moisture was measured using a moisture probe with $6 \mathrm{~cm}$ prongs

164 (Theta probe ML2x connected to HH2 moisture meter, Delta-T Devices). At the Lonielist site,

165 dipwells were inserted within a metre of each collar, and the water level was monitored

166 manually at the same time as the spectral measurements were taken. A lollipop thermometer

167 (Fisherbrand, accurate to $\pm 1^{\circ} \mathrm{C}$ ) was used to measure soil temperature outside the collar at two

168 different depths, $5 \mathrm{~cm}$ and $15 \mathrm{~cm}$. The thermometer was also used to measure temperature

169 within the vegetation inside the chamber at the start and end of each flux measurement. These

170 measurements were taken on the same dates and at the same plots as other monitoring (above).

171 To consider the different vegetation communities of the microforms, the species within the

172 collars were surveyed in June 2017. All species were recorded as percentage cover over the

173 area of the collar, and overlapping canopies sometimes allowed total percentage cover to be

174 over $100 \%$. Six species which were found at all three sites were selected as indicators of

175 microform vegetation communities. These are shown in Table I.

Table I - species selected which were present at all three sites, which microform they prefer, and their average

\begin{tabular}{|c|c|c|c|c|c|}
\hline $\begin{array}{l}\text { Common } \\
\text { name }\end{array}$ & Latin name & $\begin{array}{l}\text { Hummock or } \\
\text { Hollow }\end{array}$ & Lonielist & Talaheel & $\begin{array}{l}\text { Cross } \\
\text { Lochs }\end{array}$ \\
\hline Heather & Calluna vulgaris & Hummock & $\begin{array}{l}7.5 \pm 11.7 \\
\%\end{array}$ & $\begin{array}{l}4.7 \pm 9.8 \\
\%\end{array}$ & $\begin{array}{l}9.7 \pm 9.5 \\
\%\end{array}$ \\
\hline $\begin{array}{l}\text { Common } \\
\text { cotton grass }\end{array}$ & $\begin{array}{l}\text { Eriophorum } \\
\text { angustifolium }\end{array}$ & Hollow & $\begin{array}{l}10.9 \quad \pm \\
13.6 \%\end{array}$ & $\begin{array}{l}17.9 \pm 15 \\
\%\end{array}$ & $\begin{array}{l}9.4 \pm 10.5 \\
\%\end{array}$ \\
\hline $\begin{array}{l}\text { Reindeer } \\
\text { lichen }\end{array}$ & Cladonia portentosa & Hummock & $\begin{array}{l}12.8 \pm 18 \\
\%\end{array}$ & $\begin{array}{l}17.6 \quad \pm \\
26.9 \%\end{array}$ & $\begin{array}{l}11.4 \quad \pm \\
18.2 \%\end{array}$ \\
\hline $\begin{array}{l}\text { Red } \\
\text { bogmoss }\end{array}$ & $\begin{array}{l}\text { Sphagnum } \\
\text { capillifolium }\end{array}$ & Hummock & $\begin{array}{l}19.9 \quad \pm \\
22.5 \%\end{array}$ & $\begin{array}{l}16.7 \quad \pm \\
30.1 \%\end{array}$ & $\begin{array}{ll}27.7 & \pm \\
18.1 \% & \end{array}$ \\
\hline $\begin{array}{l}\text { Red- } \\
\text { stemmed } \\
\text { feather } \\
\text { moss }\end{array}$ & Pleurozium schreberi & Hollow & $\begin{array}{l}12.3 \quad \pm \\
22.1 \%\end{array}$ & $\begin{array}{l}23.6 \quad \pm \\
27.9 \%\end{array}$ & $\begin{array}{l}3.9 \pm 7.2 \\
\%\end{array}$ \\
\hline
\end{tabular}




\begin{tabular}{|l|l|l|l|l|l|}
\hline Deer grass & $\begin{array}{l}\text { Trichiophorum } \\
\text { germanicum }\end{array}$ & Hollow & $\begin{array}{l}0.6 \pm 2.5 \\
\%\end{array}$ & $\begin{array}{l}4.9 \pm 8.3 \\
\%\end{array}$ & $\begin{array}{l}21.8 \\
21.6 \%\end{array}$ \\
\hline
\end{tabular}

179

\subsection{Eddy Covariance}

181 Eddy covariance data from the whole of 2017 was used, except for Lonielist where data 182 collection began on the $24^{\text {th }}$ of March.

183 Net ecosystem exchange of $\mathrm{CO}_{2}$ (NEE) at Lonielist was measured using a LI-7200 enclosed $184 \mathrm{CO}_{2} / \mathrm{H}_{2} \mathrm{O}$ infrared gas analyser (LI-COR Biosciences Inc. Lincoln, NE, USA), and a Gill HS50 3-D sonic anemometer (Gill Instruments, Lymington, UK). Data was collected at $20 \mathrm{~Hz}$ frequency and recorded every half-hour onto a 16GB USB by the LI-7550 Analyzer Interface Unit (LICOR Biosciences, Inc. NE, USA). An insulated 1-meter intake tube was used and the flow was controlled by the Flow Module (7200-101, Li-Cor Inc., Nebraska, USA) to be about 15L/min. The instruments were mounted on top of a scaffolding-tower at $2.90 \mathrm{~m}$ height, pointing into the predominant wind direction (W-SW, $240^{\circ}$ North offset).

191 At Talaheel, NEE was measured using the LI-7500A open path $\mathrm{CO}_{2} / \mathrm{H}_{2} \mathrm{O}$ gas analyser (LI-

192 COR Biosciences Inc. Lincoln, NE, USA) with a custom enclosure added to the analyser to 193 create an enclosed system (Clement et al., 2009), and a CSAT sonic anemometer (Campbell

194 Scientific, Logan, USA) (Hambley et al., 2019). Data was measured at $10 \mathrm{~Hz}$ frequency and recorded every half-hour on a flash-card by the CR5000 datalogger. Instruments were set-up at $4.3 \mathrm{~m}$ height on a scaffolding tower.

197 At Cross Lochs NEE was measured by the IRGASON - an open-path infra-red gas analyser 198 integrated into a 3D-CSAT anemometer, and controlled by the EC100 electronics control 199 module (Campbell Scientific Ltd. UK). Data was measured at 10Hz, processed by the onboard

200 EasyFluxDL software (Campbell Scientific Ltd. UK) into half-hourly corrected and averaged 201 fluxes and recorded on a flashcard by the CR3000 datalogger. EasyFluxDL software processes 
the EC data using commonly used corrections in the scientific literature (Campbell Scientific, 2016). The instruments were set up at $2.3 \mathrm{~m}$ height on a tri-pod tower, pointing $310^{\circ} \mathrm{NW}$ in the predominant wind direction.

The flux data collected by the EC systems at Lonielist and Talaheel were processed using the EddyPro® software (v7.0.4, Li-Cor Inc, Nebraska, USA), in Express mode, on a PC in the office. Similar to EasyFluxDL, EddyPro® uses the most accepted and cited techniques in scientific literature to compute fully-processed half-hourly fluxes. For more details on EddyPro®, please see the EddyPro® manual (LI-COR Biosciences, 2017) and Fratini and Mauder (2014). The processed half-hourly NEE fluxes from all three sites were further processed in a custom R-software script (R Core Team, 2018) to quality check the data making sure that each half hour had at least $80 \%$ of records, that each half hour NEE value was within 3.5 standard deviations of the running 10-hour means and that the data was within physically plausible values for each ecosystem. Using R-code adapted from "http://footprint.kljun.net/download.php" [November 2018]), a flux footprint analysis was performed following Kljun et al. (2015) to ensure that all fluxes originated from within $80 \%$ of the area of interest. Footprint filtered NEE fluxes were gap-filled and partitioned into GPP and Re, following the methods and code (REddyProc, R-script) of Wutzler et al. (2018). This script also estimated the u-star threshold for the data, which was used to further filter out data during times of low turbulence, before partitioning and gap-filling.

Measurements at Lonielist began in March, so $23 \%$ of the data was missing at the start of the 2017 year. $26 \%$ of available (13550 hh) NEE half-hours were gap-filled at Lonielist, $52 \%$ at Talaheel (of $17520 \mathrm{hh}$ ), and 60\% at Cross Lochs (of 17520hh).

For comparison with the chamber and spectrometer data (TG1, see Section 2.7), the EC halfhourly data covering the same time periods as the chamber flux measurements were used, doubled to give an hourly timestep. For comparison with the TG model using MODIS data 
227 (TG2, see Section 2.7), the EC fluxes were averaged across 8-day periods and then multiplied 228 to give daily values, following Lees, Quaife, et al. (2019).

229

230

231

232

233

234

235

\subsection{Satellite data}

The Moderate Resolution Imaging Spectroradiometer (MODIS) on satellite Terra was used in this study as an example of a medium resolution broad band satellite, which is widely used in environmental studies. Pixels containing the EC towers were downloaded for this analysis. Two MODIS products were used in this study, the $250 \mathrm{~m}$ MOD13Q1 NDVI product (Didan, 2015), and the $1 \mathrm{~km}$ MOD11A2 Daytime Land Surface Temperature (LST) product (Wan, Hook and Hulley, 2015). The NDVI product is given in 16-day periods, whilst the LST product is given in 8-day periods. The MODIS data products were downloaded using the MODIS ORNL web service through Matlab code (Santhana Vannan et al., 2009). Cloud filtering was applied to remove pixels extensively affected by cloud cover, whilst letting through data which was affected by clouds but still useable (Lees, Quaife, et al., 2019). Each of the MODIS products contains information about the quality of the data in each pixel, and this was used to select which 8-day or 16-day pixels were useable. MOD13Q1 pixel reliability index was used to remove snow/ice or cloud affected values, whilst allowing marginal data. MOD11A2 quality control data was used to remove periods when data was not produced due to cloud effects or other issues. $17-50 \%$ of the data at each site were excluded following this protocol. Gap-filling was then performed across each year using the techniques described by Wang et al. (2012), before combining the data into the TG model.

\subsection{The TG model}

The Temperature and Greenness (TG) model combines a measure of temperature with a vegetation index to give an estimate of GPP (Sims et al., 2008). The model is formulated 
250 following Moore et al. (2013), but using NDVI following the results of Lees, Quaife, et al. 251 (2019):

252 GPP $=$ NDVIs $\times$ LSTs $\times$ m

$253 \quad$ NDVIs $=$ NDVI -0.1

254 LSTs $=\min [($ LST-minLST $) /($ optLST-minLST $),(\operatorname{maxLST}-L S T) /(\operatorname{maxLST}-$ optLST $)]$

255 Where NDVIs is the scaled Normalised Difference Vegetation Index and LSTs is the scaled 256 Land Surface Temperature (see Sims et al., 2008; Lees, Quaife, et al., 2019). The scaled NDVI 257 removes low values of NDVI which show no GPP. minLST, optLST and maxLST (given in $258{ }^{\circ} \mathrm{C}$ ) are the minimum, optimum and maximum Land Suface Temperature calculated for a 259 specific ecosystem. We have used $40^{\circ} \mathrm{C}, 25^{\circ} \mathrm{C}$ and $-2.5^{\circ} \mathrm{C}$ for maxLST, optLST and minLST 260 respectively, following Lees, Quaife, et al.'s (2019) work on the same study sites. Furthermore,

261 ' $\mathrm{m}$ ' is a site-optimisation parameter, and the GRG Nonlinear Solver in Microsoft Office Excel 2622013 was used to optimise this parameter at both small and large scales (see Section 4 for 263 discussion of calibration).

264 Three different formulations of the TG model are used in this study to assess the effect of scale 265 versus methodological bias. These versions are:

266 TG1 - Small-scale TG model using spectrometer data

267 The 'm' parameter for the TG model using spectrometer data was optimised to the chamber 268 data across all months and sites and was given the value 0.4397. This small-scale version of 269 the TG model gives an estimate of GPP per hour. 
271 The ' $m$ ' parameter for the TG model using MODIS data was optimised to the EC data across

272 the whole of 2017 (where EC data was available) and across all three sites. It was given the

273 value 8.046. This large-scale version of the TG model gives an estimate of GPP per day.

\section{$274 \quad$ TG3 - Small-scale TG model using MODIS data}

275 The small-scale ' $m$ ' parameter was applied to the large-scale TG model to give an hourly 276 estimate of GPP using MODIS data.

\section{2.8. Statistical analysis}

278 An Exploratory Factor Analysis (EFA) was used to simplify the large range of variables measured which could affect GPP on a small scale. EFA is a variable reduction technique designed to draw out the underlying factors affecting the measured variables. In this case the EFA was used because we expected that the variables measured were related to each other by means of underlying constructs, for example, the presence of certain vegetation species was likely to be correlated due to underlying features of their microhabitats.

The variables considered included those explained in Section 2.4 (selected vegetation species, PAR, surface temperature, soil temperature at $5 \mathrm{~cm}$ and $15 \mathrm{~cm}$, soil moisture, and microforms), and also the NDVI, which is a measure of vegetation greenness and health, and the Normalised Difference Water Index (NDWI, using NIR and Short-Wave Infrared (SWIR)) which has been shown to have a relationship with moisture conditions in peatland vegetation (Lees et al., 2019). Repeated measures were accounted for by including the time of year as a variable; in order to create a linear relationship, daylight period was used as a measure of season. These variables are referred to in the results by short names given in Table II.

\begin{tabular}{|l|l|}
\hline Short name & Description \\
\hline Feather_moss & The proportion of P schreberi in the collar (\%) \\
\hline
\end{tabular}




\begin{tabular}{|l|l|}
\hline Reindeer_lichen & The proportion of C portentosa in the collar (\%) \\
\hline S_cap & The proportion of S capillifolium in the collar (\%) \\
\hline Deer_grass & The proportion of T germanicum in the collar (\%) \\
\hline Cotton_grass & The proportion of E angustifolium in the collar $(\%)$ \\
\hline Heather & The proportion of $C$ vulgaris in the collar $(\%)$ \\
\hline NDWI & The calculated NDWI of the collar from the hand-held spectrometer \\
\hline NDVI & The calculated NDVI of the collar from the hand-held spectrometer \\
\hline PAR & The average PAR across the clear chamber flux measurement period. \\
\hline Surface_temp & The temperature amongst the vegetation at the soil surface $\left({ }^{\circ} \mathrm{C}\right)$ \\
\hline Soil_temp_5cm & The soil temperature at $5 \mathrm{~cm}$ depth $\left({ }^{\circ} \mathrm{C}\right)$ \\
\hline Soil_temp_15cm & The soil temperature at $15 \mathrm{~cm}$ depth $\left({ }^{\circ} \mathrm{C}\right)$ \\
\hline Light_period & Daylight period of the day of measurement in Scotland \\
\hline microfeature & $\begin{array}{l}\text { Whether the collar was on a high area (hummock/ridge) or low area } \\
\text { (hollow/ditch) }\end{array}$ \\
\hline
\end{tabular}

293

294 The EFA was limited to five factors after initial statistical exploration of different numbers of

295 factors suggested that this was the best option for all three sites; we found that using five factors

296 explained the majority of the variance seen in variables at each site (see supplementary

297 material). The resulting factor scores were correlated with the GPP in order to assess which

298 factors and variables were most important in determining peatland GPP at small scales, and

299 whether these could be assessed using remote sensing.

300 All analysis was done in base R (R Core Team, 2017). All results collected specifically for this

301 study are available online (Lees, Clark, et al., 2019).

\section{Results}

303 3.1. Factors affecting GPP at small scale

304 The six vegetation species considered in this analysis show several significant differences

305 between hummock and hollow percentage coverage (see Figure 2). At the near-natural Cross

306 Lochs (Figure 2C) site there is significantly more heather ( $C$ vulgaris) and $S$ capillifolium on 
307 the hummocks, but significantly more deer grass (T germanicum) in the hollows. The Lonielist

308 site (Figure 2A) also has significantly more heather on the hummocks, but significantly more

309 red-stemmed feather moss (P schreberi) in the hollows. There were no significant differences

310 between hummock and hollow vegetation at the Talaheel site in 2017 (Figure 2B).

311 There are also differences between the three sites in terms of vegetation cover. Cross Lochs is

312 richer in deer grass than the other two sites, whilst Talaheel has higher cover of common cotton

313 grass (E angustifolium). The intact site Cross Lochs also has a greater variety of species, with

314 some present that were not included in our collars at the other two sites such as bog myrtle

315 (Myrica gale), bog asphodel (Narthecium ossifragum), and sundew (Drosera rotundifolia). 
A - Lonielist

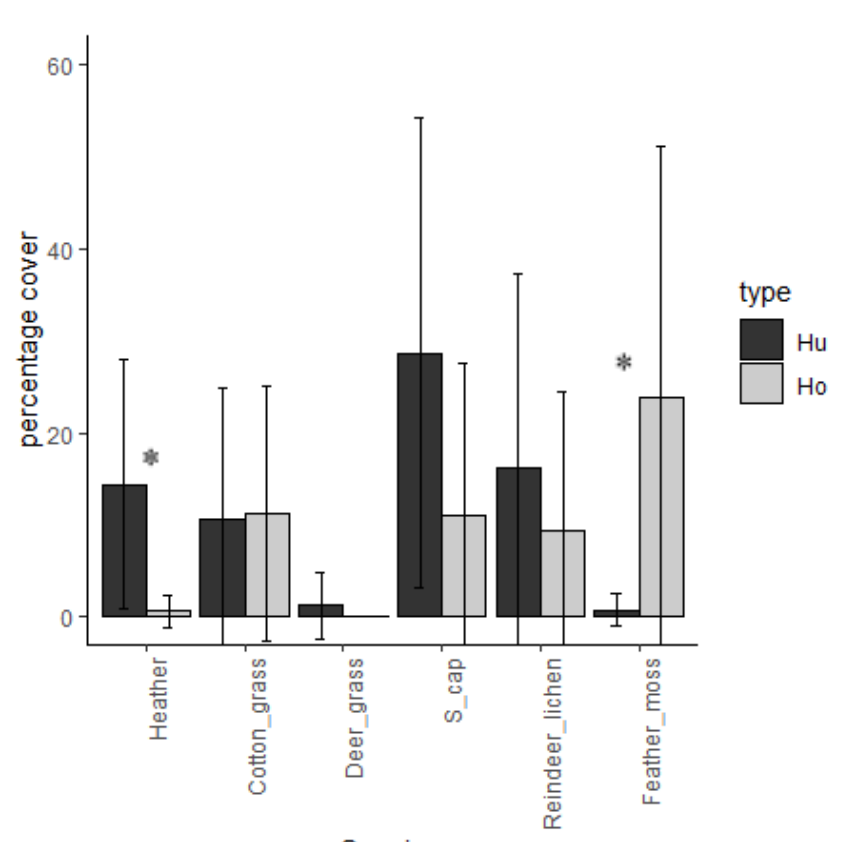

316

Species

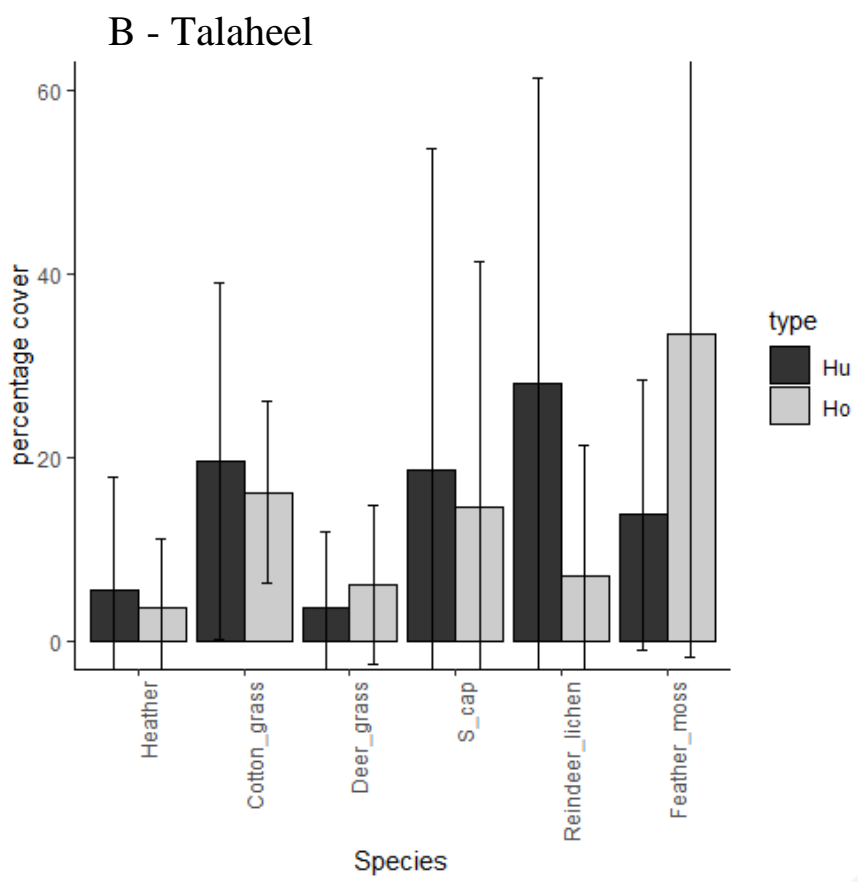




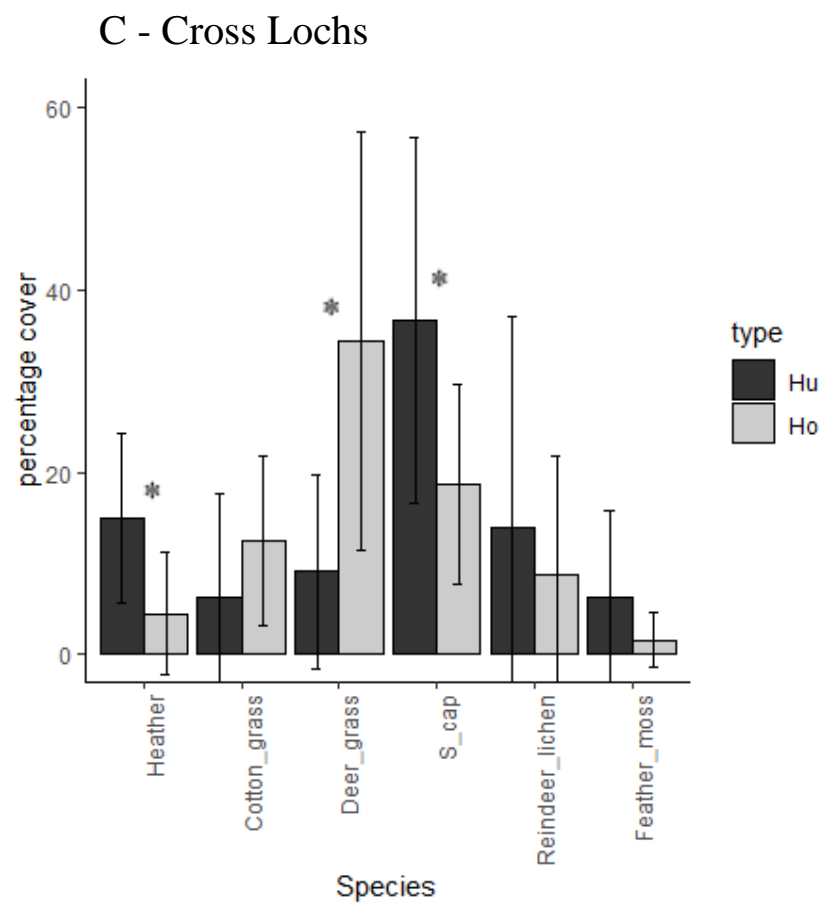

Figure 2 -Species differences between hummocks and hollows at the three sites (A: Lonielist, B: Talaheel, C: Cross Lochs). Stars show significant difference between hummock and hollow $(n=8, p<0.05)$.

These selected vegetation species were also used in the EFA, where they are linked to underlying factors which also affect microtopography (all sites), the NDWI (Talaheel and Cross Lochs), and soil moisture (Cross Lochs). These factors also correlate with GPP.

The EFA results are shown in Figure 3, along with the factor Pearson's correlations with GPP. At Lonielist (Figure 3A) the second factor has the highest correlation with GPP (0.68) and is linked with the NDVI and the three temperature variables. The third and fourth factors also show some correlation with GPP $(0.21,0.28)$ and are connected with the microforms variable and the vegetation species variables.

330 At Talaheel (Figure 3B) the first and third factors show correlations with GPP $(0.45,0.25)$. The

331 first factor is connected to the NDVI, NDWI, and temperature variables, whilst the third is 332 linked with the NDWI and NDVI, and percentage cover of S. capillifolium, reindeer lichen, 333 and feather moss. 
334 At Cross Lochs the first factor is correlated with GPP (0.49) and links with light period, 335 temperature, NDWI and PAR. The second factor also correlates with GPP $(-0.22)$ and is 336 connected to the microform variable, several plant species, soil moisture and the NDWI. The

337 negative correlation here suggests that the collars classed as hollows have a higher GPP than 338 those classed as hummocks; this is opposite of the result at Lonielist. The third factor correlates 339 positively with GPP (0.38) and is connected to the two soil temperature variables, NDWI and 340 NDVI.

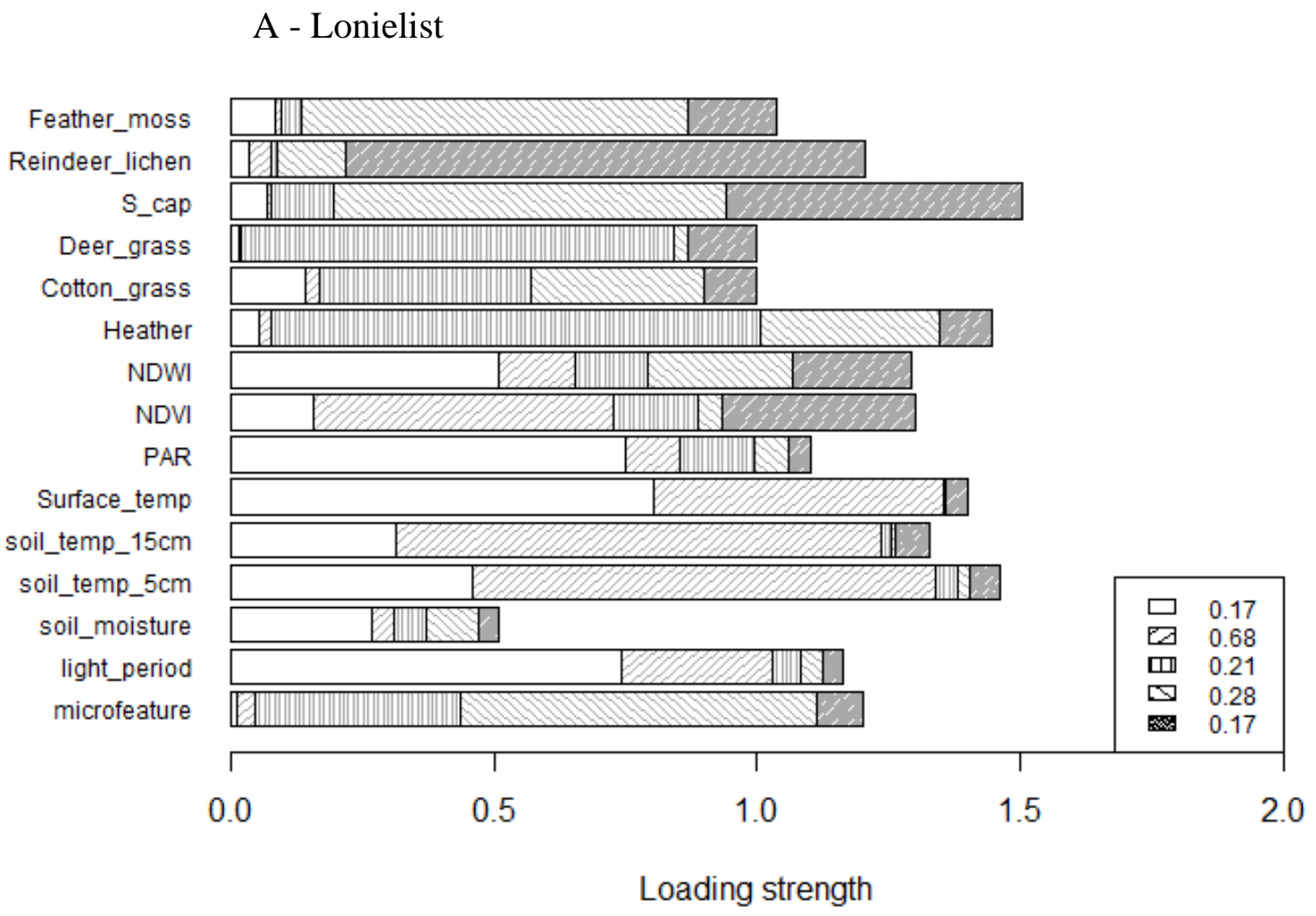




\section{B - Talaheel}

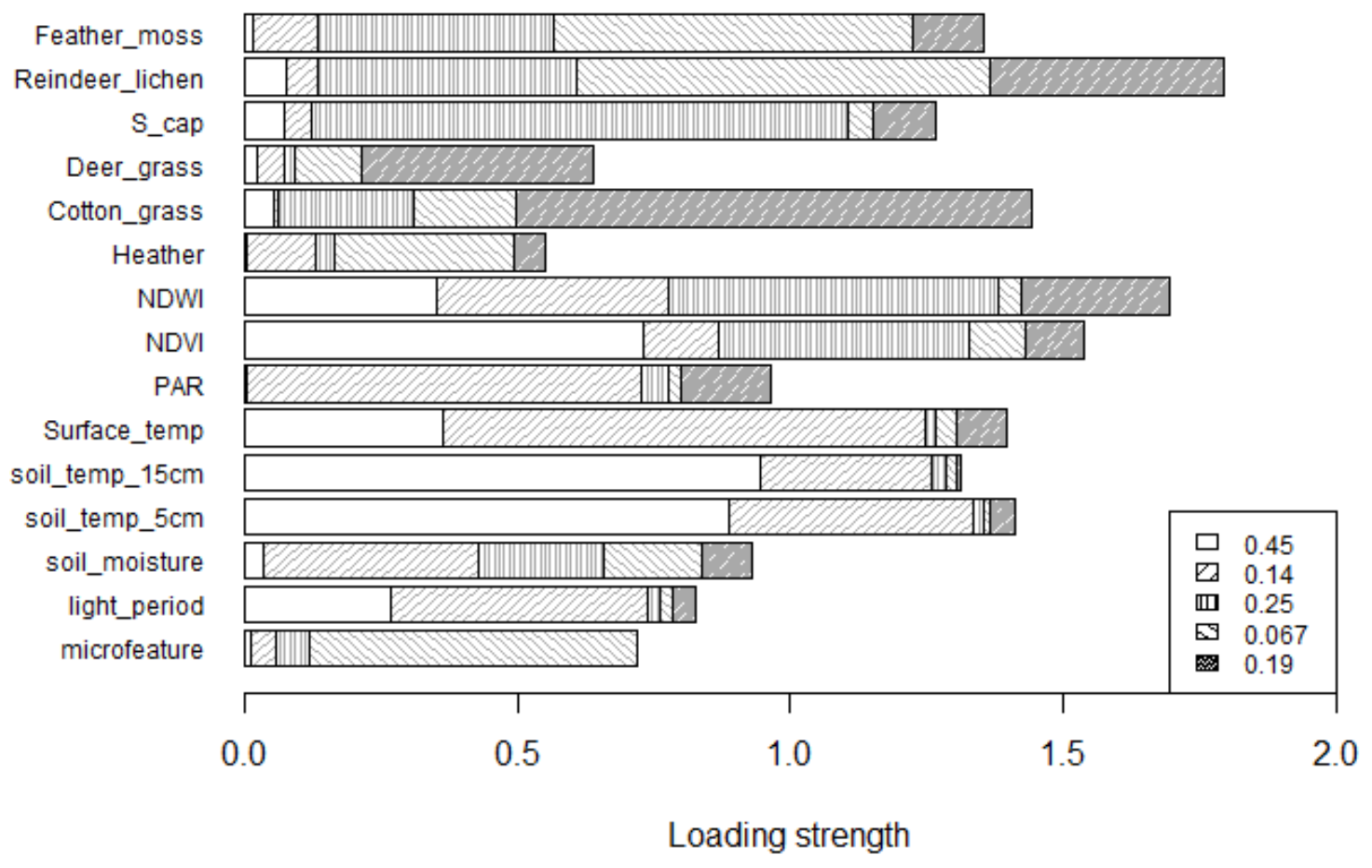

\section{C - Cross Lochs}

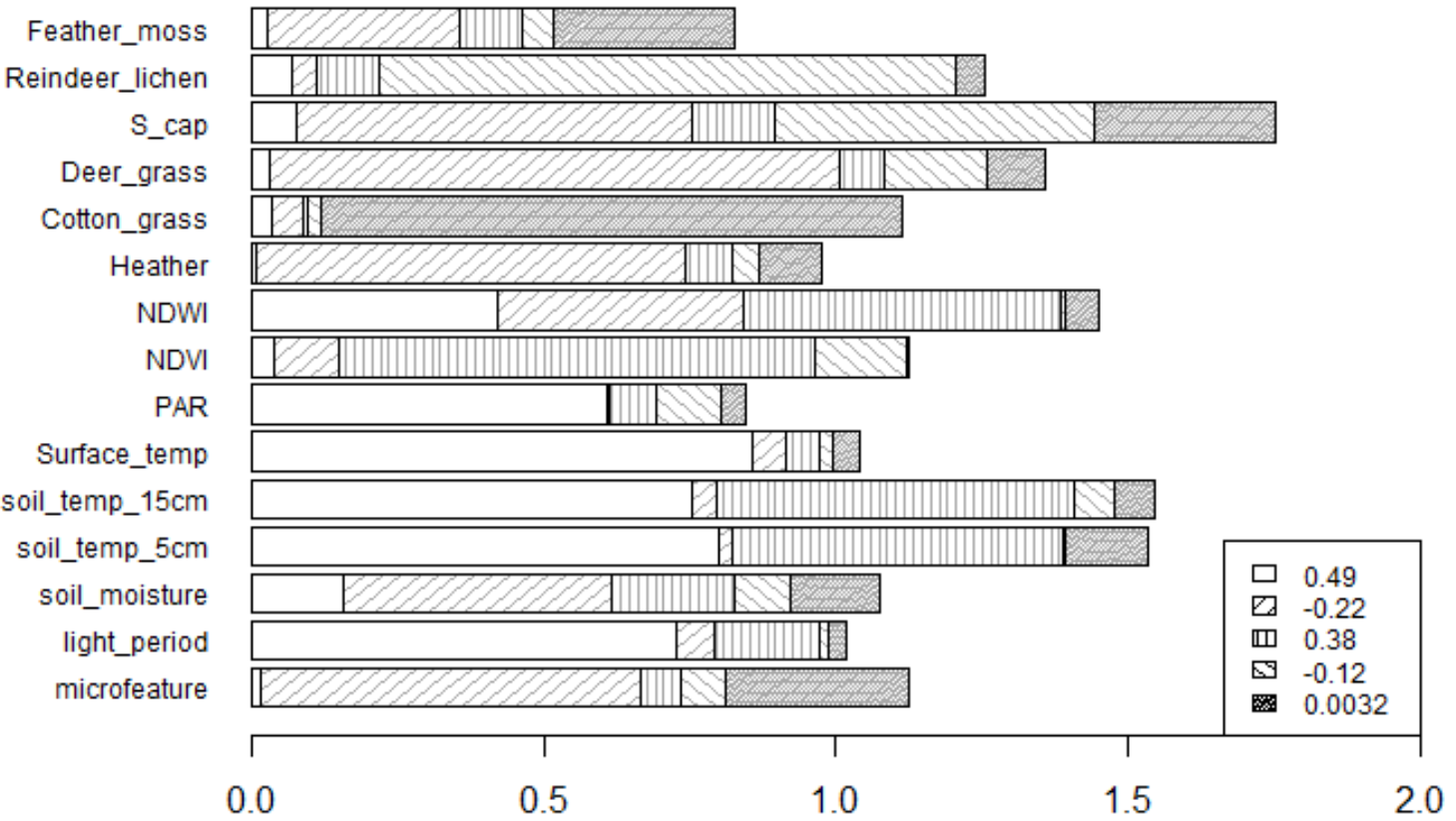

Figure 3 - Lonielist, Talaheel and Cross Lochs factors. Each of the five factors is indicated by a different pattern fill. The variables are given on the y axis, and the factors which underly and are connected with each variable have a loading strength shown by the stacked bar lengths. Legends show correlation of the scores for each factor with GPP values. For example, the first factor at Cross Lochs is shown by the white bars, and has 
high loading strengths associated with PAR, the three temperature variables, and the light period. It also has a correlation of 0.49 with GPP. See supplementary material for more information.

350

351

\subsection{Comparison of modelled and measured GPP at small scale}

352 Figure 4 shows the TG model using the spectrometer NDVI and the surface temperature

353 applied to each of the sites across the measurement period, with the ' $\mathrm{m}$ ' parameter calibrated

354 to the chamber data (TG1). The agreement between the model and the chamber data is very

355 good temporally, with the boxplots well within error bars across the year. The chamber fluxes

356 have larger ranges than the TG model results at each site throughout the growing season. The

357 TG model tends to underestimate the highest chamber GPP values, as can be seen from the

358 scatter plots in Figure 4. 

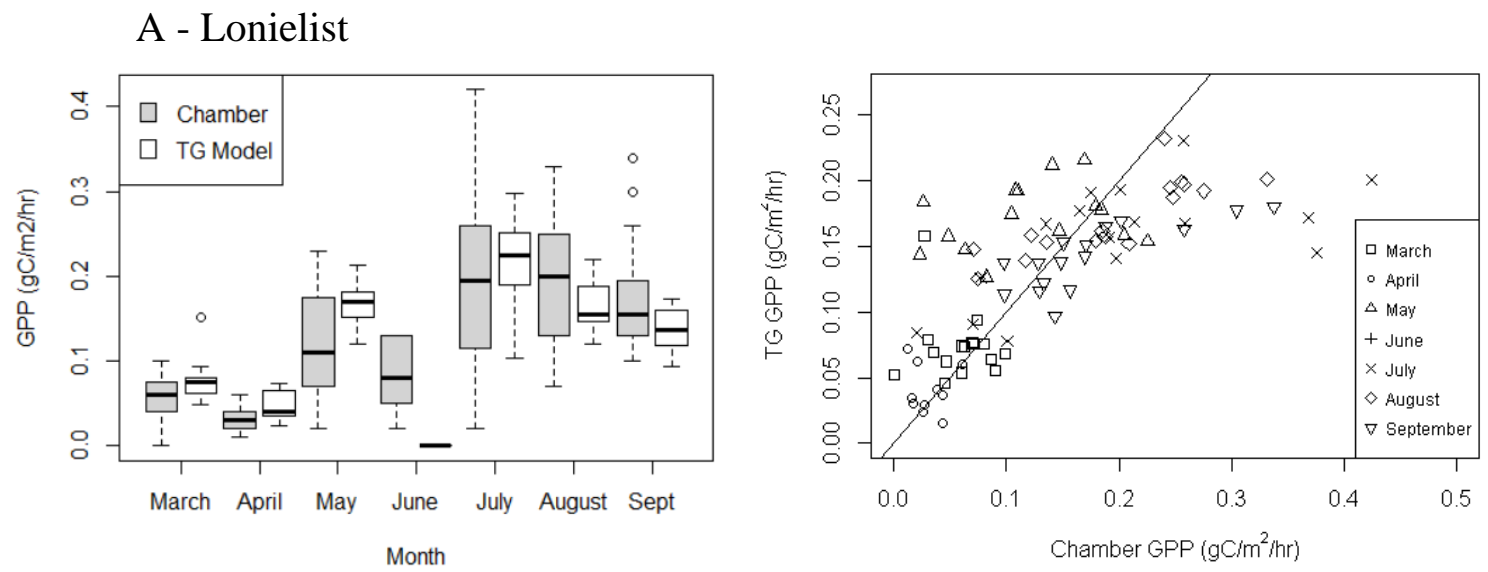

\section{B - Talaheel}
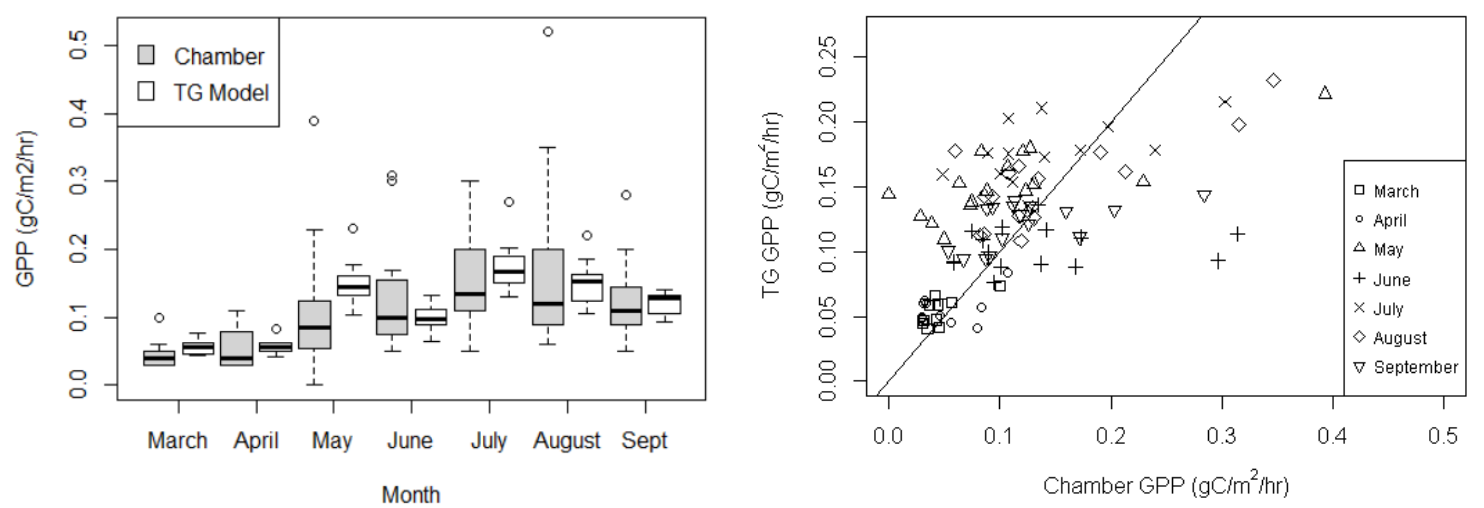

\section{C - Cross Lochs}
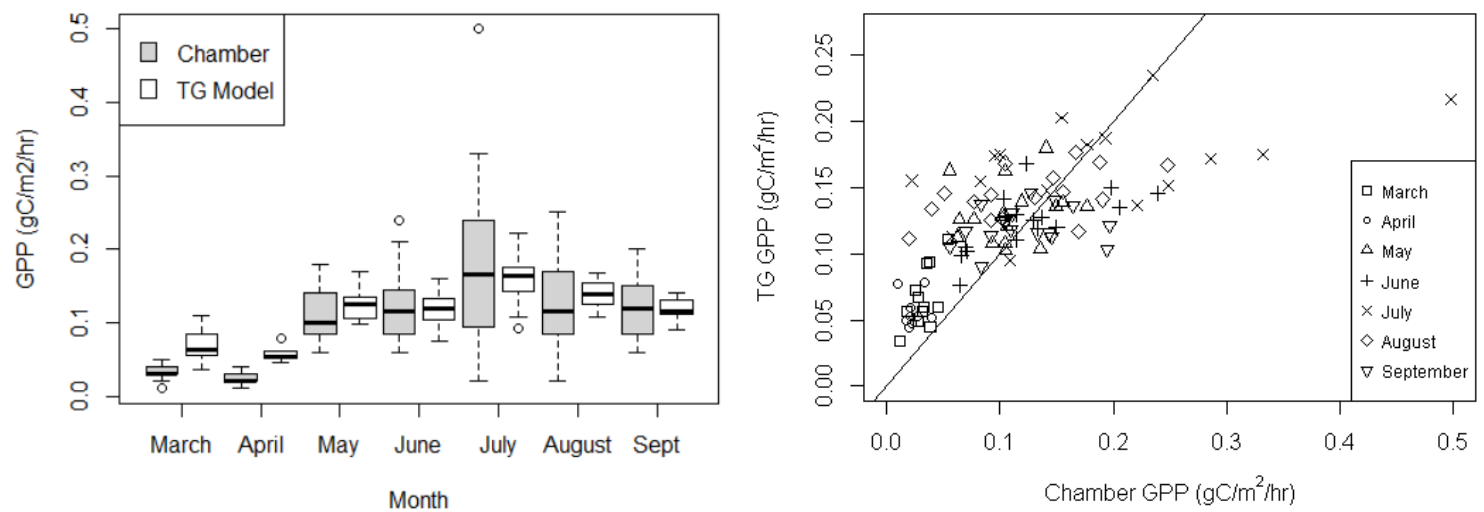

Figure 4 - Boxplots and scatterplots (by month) comparing the chamber-measured GPP and GPP calculated from the TG model using hand-held spectrometer data and the surface temperature measurements for each site

(TG1). There is no TG model result in June at Lonielist due to the poor weather causing lack of spectral measurement. 1:1 lines are plotted on the scatter graphs. 
366 Figure 5 shows the average GPP across the experiment period from the chamber data and EC

367 data, and modelled from the spectrometer (TG1) and MODIS (TG2 and TG3) data. The

368 Pearson's correlations between the chamber fluxes and the spectrometer TG1 fluxes across all 369 months are $0.57(\mathrm{p}<0.01, \mathrm{n}=98)$ at Talaheel, $0.71(\mathrm{p}<0.01, \mathrm{n}=89)$ at Lonielist, and $0.70(\mathrm{p}<0.01$, $370 \mathrm{n}=101)$ at Cross Lochs. TG2 using MODIS data is calibrated on a daily rather than hourly time 371 frame, and the Pearson's correlations between the EC data and the MODIS TG2 model (DoY 37270 to 265$)$ are $0.76(\mathrm{p}<0.01, \mathrm{n}=23)$ at Lonielist, $0.76(\mathrm{p}<0.01, \mathrm{n}=24)$ at Cross Lochs, and 0.86 $373(\mathrm{p}<0.01, \mathrm{n}=24)$ at Talaheel.

374 The chamber GPP is lower than the time-period-matched EC GPP at all three sites (54.9\% 375 lower at Lonielist, $72 \%$ at Talaheel, $62 \%$ at CrossLochs). The TG3 model using MODIS data 376 and the ' $m$ ' parameter calibrated from small-scale data matches better with hourly chamber 377 fluxes than EC fluxes.

378 The difference between chamber GPP from hummocks and hollows is greatest at Lonielist and 379 shows higher GPP values from hummocks. The difference is less pronounced at Cross Lochs, 380 but shows the opposite effect, with higher GPP from hollows. Talaheel shows less clear 381 differences between the two types of microform. At all three sites the differences in 382 microtopography shown by the spectrometer TG results are less pronounced than those from 383 the chambers. As the differences between GPP from hummocks and hollows are small and 384 inconsistent, area-weighting was not used in upscaling estimates for this study. 


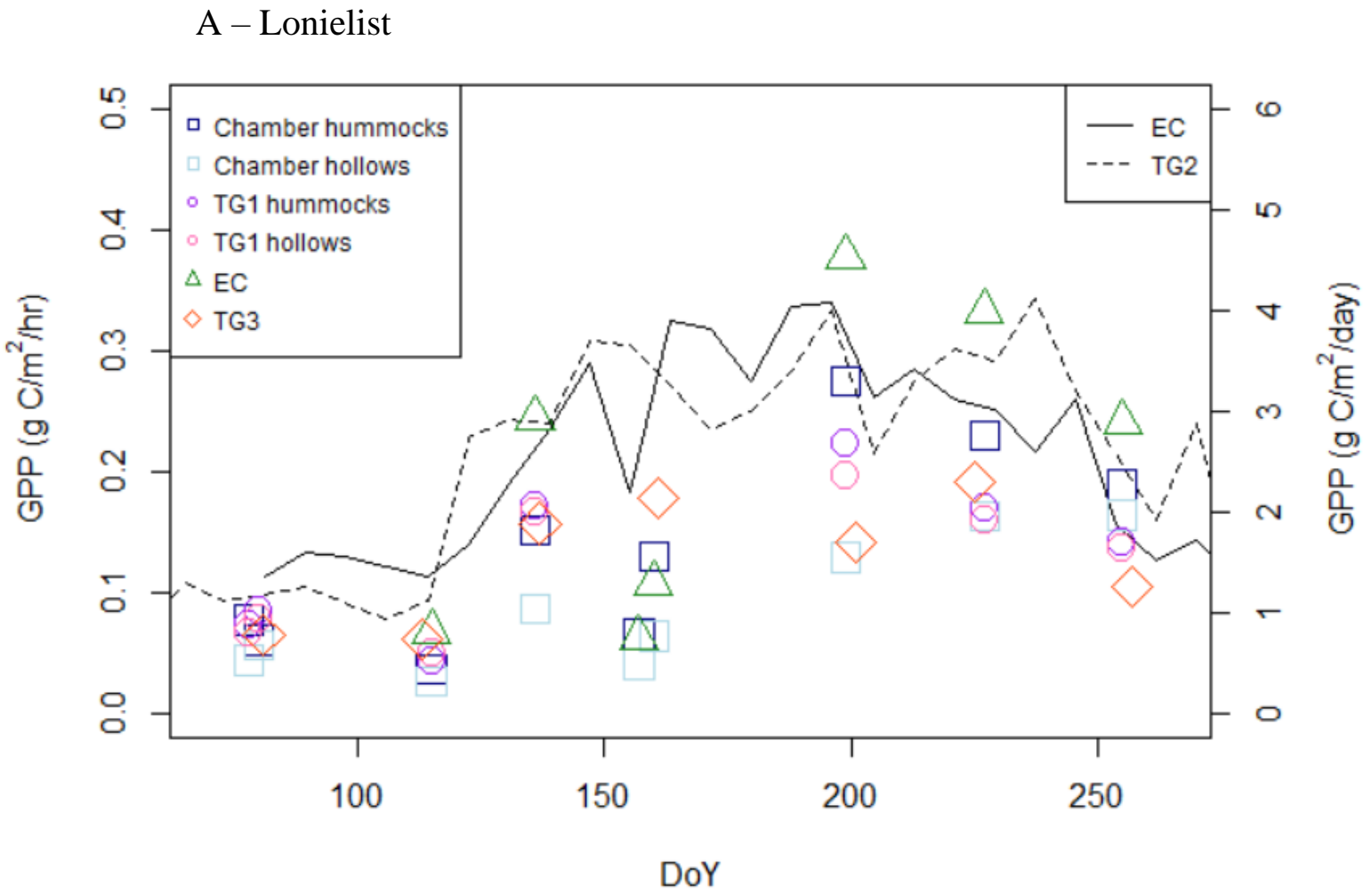

B - Talaheel

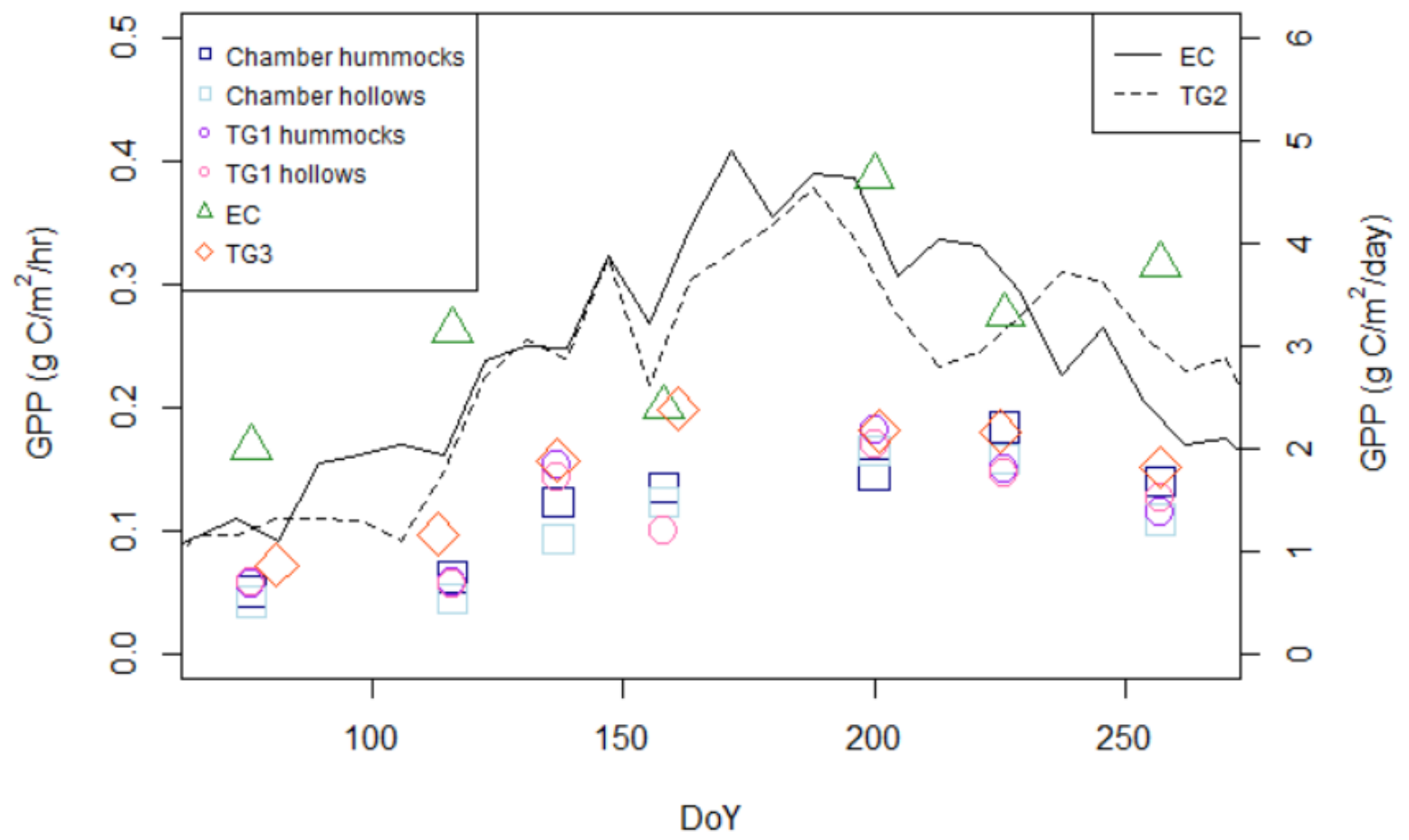




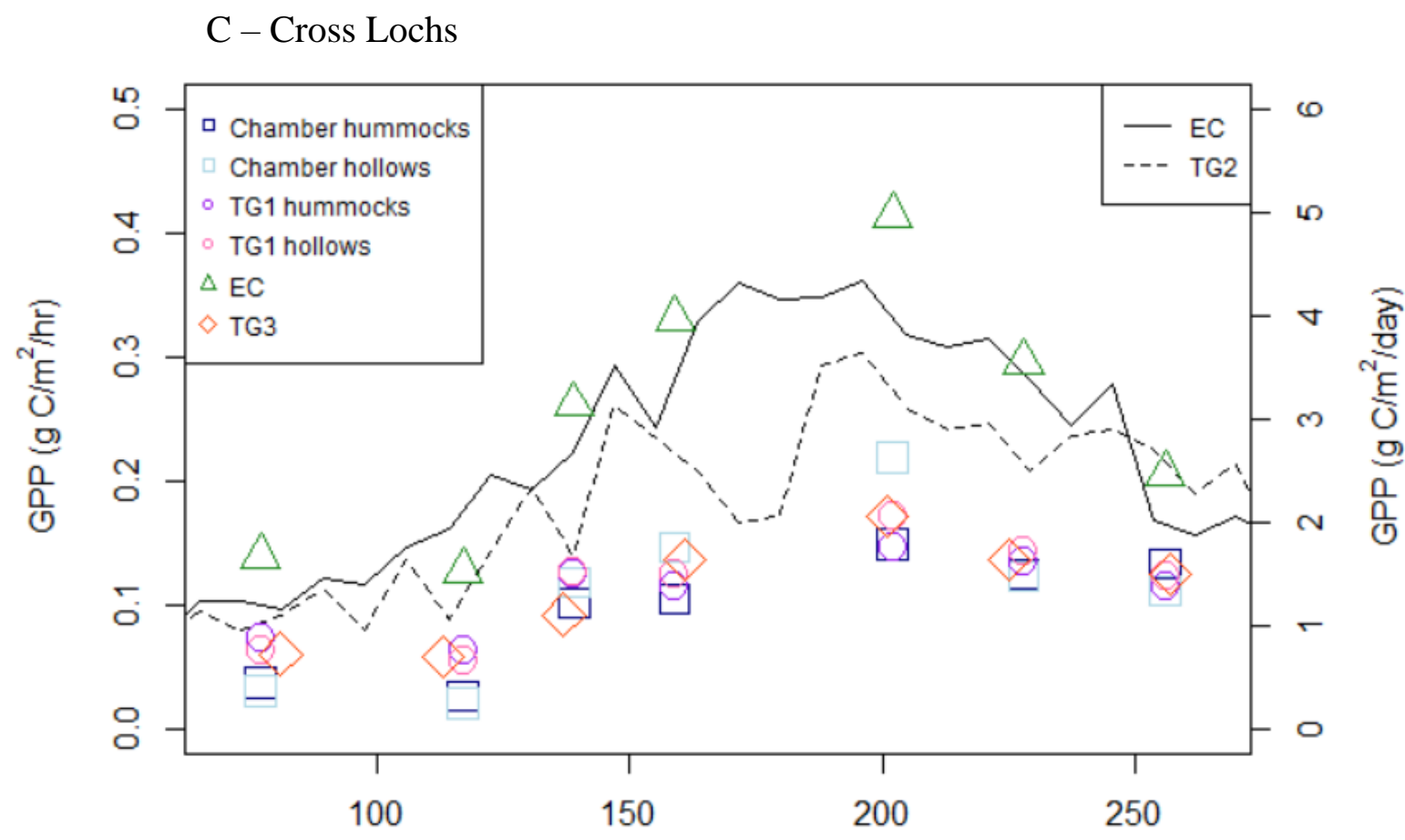

Figure 5 - The different estimates of GPP for each site across the growing season. The results represented by coloured symbols and the left-hand axes show the measurements and model results that are calibrated to an hourly timestep and only calculated during manual field measurement periods. These include the flux chamber data from hummocks and hollows, the TG1 model results for hummocks and hollows, the EC data averaged across the half-hourly periods covering the chamber flux measurement period, and the TG3 model. The results

represented by the black lines and the right-hand axes show the measurements and model results that are calibrated to a daily timestep and are continuous across the growing season of 2017 due to automated measuring systems. These include the EC data averaged over 8-day periods, and the TG2 model. 
401 The EFA correlations with GPP showed that the NDVI and temperature were dominant in the

402 factors affecting GPP at all sites. This endorses the use of the TG model, which makes use of both 403 these variables. All three temperature variables, at surface, $5 \mathrm{~cm}$ and $15 \mathrm{~cm}$, were included as 404 variables, but they are strongly related and only one is necessary in the model. The surface 405 temperature provides much more short-term variation compared to soil temperature, and has a 406 relationship with the incoming radiation available for photosynthesis, as shown by the EFA. The 407 variation which surface temperature adds to the model is therefore more than seasonal change, and 408 can provide information on day-to-day changes in GPP due to weather and radiation, and even 409 changes throughout the day.

410 Lonielist GPP results at small scale showed the greatest difference between hummocks and 411 hollows, particularly in July when we had clear skies and high temperatures during the 412 measurement period. This difference may be more evident at Lonielist than the other sites due to 413 the relic furrow and ridge system creating more extreme microtopographical features than would 414 otherwise be found in a blanket bog. Wu et al. (2011) found that there was no difference in 415 simulated GPP using the McGill Wetland Model between hummocks and hollows at the Mer Bleue 416 bog in Canada, consistent with our results from Talaheel, but did find a significant difference in 417 respiration with hummock ecosystem respiration higher than hollows. They showed that shrubs 418 were the dominant influence on hummock carbon cycling, whilst mosses were the dominant factor 419 in hollows. In contrast, Waddington and Roulet ( 1996) used flux chamber measurements to show 420 that hummocks at their study site in a Swedish peatland had greater $\mathrm{CO}_{2}$ uptake than hollows 421 during the growing season, similar to our results at Lonielist. It is somewhat surprising that Cross 422 Lochs, the near-natural site, showed a small but opposite difference in fluxes between microforms. 
423 Lindsay et al. ( 1988) found that some areas of the Flow Country were dominated by pool and

424 hollow type landforms due to the wet climate, and it may be the case that our classifications of

425 landforms at Cross Lochs were based on the need to distinguish areas of different heights within

426 close range, and did not always satisfy the descriptions of true hummocks and hollows. In general,

427 the differences in GPP fluxes between microforms did not seem to be large or temporally

428 consistent during our study period. The period during which measurements were taken was

429 generally quite wet, with June, July and August all having higher rainfall totals than the 1981-2010

430 average (Met Office, 2012, 2018). A stronger difference between fluxes from microforms might

431 have been seen under dryer conditions. This is corroborated by previous studies that have found

432 significant differences between carbon fluxes from different microforms linked to soil moisture

433 (Heikkinen et al., 2002; Laine et al., 2006). Despite small differences in GPP among the chamber

434 locations, we did observe significant differences in vegetation between the microtopographical

435 features at Lonielist and Cross Lochs, and also in general between the sites. The significant

436 differences in selected vegetation species are consistent with their preferred microhabitats. Both

437 Lonielist and Cross Lochs show a greater proportion of heather ( $C$ vulgaris) on the higher areas of

438 ground. Cross Lochs has higher percentages of $S$ capillifolium, a Sphagnum species well known

439 to be hummock forming (Laine, 2009) on the higher areas, and more deer grass (T germanicum)

440 in the hollows, whilst Lonielist has significantly more red-stemmed feather moss (P Schreberi) in

441 the furrows. It is worth noting that there is ecological succession in play as well as

442 microtopographical features when we consider these three sites, as shown in Hancock et al. (2018).

443 The presence of deer grass ( $T$ germanicum) seems to be associated more with the near-natural site

444 at Cross Lochs, whilst Talaheel has higher relative proportions of common cotton grass $(E$

445 angustifolium) which has been found to colonise disturbed areas of ground (Phillips, 1954). 
446 Malhotra et al. (2016) similarly found that there was there was a clear relationship between

447 microtopography and species distribution at the Mer Bleue bog in Canada, and that fine spatial 448 structures explained up to $40 \%$ of species distribution.

449 The selected vegetation species showed some influence on GPP, although this varied between the 450 sites. The two wetter sites, Cross Lochs and Talaheel, showed greater connections between GPP 451 and measures of moisture, both NDWI and soil moisture measured using the probe. Both Lonielist 452 and Cross Lochs showed some correlations between factors linked with microtopography and 453 GPP, although the relationship was stronger at Lonielist. Malhotra et al. ( 2016) found that water 454 table depth was a significant factor in maintaining distinct vegetation communities on 455 microtopographical features. Their work was done on the Mer Bleue bog in Canada, which can be 456 described as near-natural, and therefore is most similar to our site at Cross Lochs which also had 457 links between microtopography and soil moisture, as shown by the EFA.

458 The underestimation of the model at high GPP values evident in Figure 4 is likely due to the 459 temperature component of the TG model. Although the temperature component functions partly 460 as a proxy for PAR (as shown by the EFA), the relationship between these two factors is not always 461 linear, and this relationship may be even less strong in maritime temperate climates, where warm 462 but cloudy days occur in summer, and cold but clear days in winter. It is worth noting that the 463 presence of vegetation and water bodies can impact the LST (Solangi, Siyal and Siyal, 2019). The 464 values used in the temperature scaling equation may also be affecting the relationship between the 465 model and actual GPP values. These values were estimated visually by plotting EC values against 466 MODIS LST (see Lees, Quaife, et al., 2019), and may not be completely accurate, particularly at 467 the higher end of the temperature range where we had very little data available. 
468 There was a clear difference between the GPP values from the chambers and the EC towers, with

469 the EC data giving higher results at all three sites (Figure 5). There are many possible reasons for 470 this, including errors from the chamber methodology. The collar insertion method, which involved 471 cutting into the peat and root mass around the collar base, could have damaged the vegetation and 472 so reduced chamber fluxes. Heinemeyer et al. (2011) found that collar insertion prior to using a 473 flux chamber could reduce respiration at peatland sites by up to 30-50\%, even several months after 474 insertion. The chamber measurements were also subject to a reduction in PAR, which would have 475 resulted in a small reduction measured relative to actual GPP. Background concentrations of $\mathrm{CO}_{2}$ 476 within the chambers were monitored to ensure they were close to atmospheric levels at the start of 477 each measurement, and as the measurements were only five minutes long $\mathrm{CO}_{2}$ build-up is unlikely 478 to have affected the results. Some of the chamber data showed noise, suggesting that there were 479 minor leaks where the chamber was not perfectly sealed. The data from these measurements was 480 still useable but may show slightly lower results than the actual flux. It is possible that there were 481 some changes in chamber volume throughout the experimental period due to collar settling and 482 vegetation growth which were not accounted for in the measurements and could have led to slight 483 under or overestimation (Morton and Heinemeyer, 2018).

484 Factors affecting the EC fluxes may also be responsible for the differences seen. Cross Lochs, 485 which shows a large difference between EC and chamber GPP results, has an open path sensor 486 compared to the other two sites which have closed paths, and this may have led to inaccuracies in 487 the flux measurements as measurements were only taken during (heavy) rain-free periods and so 488 the gap filling has a degree of bias. (Helbig et al., 2016). The ecosystem respiration results are 489 similar from the chambers and the EC tower (not shown), suggesting that the difference is not 490 caused by the partitioning equations used in EC data processing. 
491 Laine et al. (2006) compared NEE from EC and chamber measurements at a blanket bog site in

492 Glencar, Ireland, which is climatically and structurally similar to the Forsinard Flows reserve, and

493 found a correlation of 0.82 between EC and interpolated chamber NEE, even when footprint size

494 and direction variation was not accounted for. They did note, however, that agreement decreased

495 towards the extremes of the temperature range, agreeing with the current work where differences

496 were particularly noticeable in the hotter measurement period in July. Griffis, Rouse and

497 Waddington (2000) also compared chamber and EC fluxes, at a subarctic fen in Manitoba. They

498 found that chamber measurements of GPP were 32\% lower than EC GPP results, similar to the

499 current work. They also showed that hummocks dominated the $\mathrm{CO}_{2}$ fluxes, which corresponds

500 with the Lonielist site showing greater agreement between hummock and EC GPP than between

501 hollow and EC GPP. Similarly, Heikkinen et al. (2002) found that carbon fluxes from chamber

502 measurements were somewhat lower than those from EC at a subarctic fen in Northern Finland.

503 Application of the TG model with MODIS data and small-scale ' $m$ ' parameter (TG3) matched

504 chamber data better than hourly EC data, suggesting that the difference between chamber and EC

505 GPP is not only a result of spatial scale. The TG model is clearly very dependent on calibration to

506 measured data, and therefore the uncertainty of measurements used in the model calibration will

507 form a large part of the uncertainty estimates of the TG model.

508 Generally, the agreement between the TG model and the measured fluxes is shown to be good at 509 small scale (TG1), with correlations of 0.57 to 0.71 . The Lonielist and Cross Lochs sites show 510 slightly better agreement than the Talaheel site. Talaheel was also the only site to show almost no 511 connection between microtopography and GPP. This may be due to the recent landscaping of the 512 site to put peat dams in the remaining planting furrows, which has created large flat areas and deep 513 pools, rather than the more natural small hummocks and hollows. It may be the case that the 
514 vegetation species have not had time since the work done in 2015/16 to develop their ecological

515 niches. It is also clear that the water levels at Talaheel have been increased by the recent plough

516 furrow blocking, and areas which we would consider hollows are often flooded and so unsuitable

517 for taking flux or spectral measurements. This may also be affecting the agreement with the model,

518 as the Talaheel site might be responding to temperature and seasonal changes differently to sites

519 which have had less recent disturbance.

520 The GPP calculated with the TG model that used data from MODIS (TG2) was strongly correlated 521 with the GPP derived from EC data (correlations of 0.76 to 0.86 ). This was in agreement with the 522 work done on developing the model in Lees, Quaife, et al. (2019). The ' $m$ ' parameter calibrated 523 for the TG model against EC data in this study, which uses data from 2017, is higher than that 524 calculated in Lees, Quaife, et al. (2019) which used 2015/16 data. This may be because the growing 525 season of 2017 was particularly wet; this supports the development of the annual Temperature, 526 Greenness and Wetness (TGWa) model (Lees, Quaife, et al., 2019), which associates high summer 527 wetness with increased annual GPP (this model was not used in this study as it is designed to give 528 a single annual estimate of GPP, and is therefore not applicable on timescales of less than a year). 529 The entirety of the available data were used for optimising the parameterisation in this model, but 530 this does not cause a type 1 error for two reasons: firstly, the ' $m$ ' parameter does not affect 531 correlation, but only estimate size. Secondly, the error size is only considered in relation to the 532 difference between chamber and EC calibration, and therefore we are not testing the accuracy of 533 the model, but whether the calibration method affects the results.

534 Several previous studies suggest that vegetation indices using finer resolution remote sensing data 535 match EC measurements of GPP better than coarser resolution data across a variety of ecosystems 536 (Fu et al., 2014; Knox et al., 2017; Gonzalez del Castillo et al., 2018). Becker et al. (2008) found 
537 that hummocks in an oligotrophic pine fen had higher GPP than lawns, and that the percentage 538 cover of hummocks was overestimated when lower resolution imagery was used, resulting in an

539 overestimate of $\mathrm{CO}_{2}$ uptake. Gatis et al. (2017), however, showed that chamber measurements of

540 GPP had strong correlations with vegetation indices calculated from both small-scale camera data

541 and large-scale MODIS data in an upland peatland environment. Similarly, we have found that

542 both small-scale spectrometer data and large-scale MODIS data can be used to give good estimates

543 of GPP in peatland landscapes, but the results are dependent on the calibration. The results of the

544 large-scale TG model using MODIS data gave an average estimate of GPP for the site based on

545 NDVI and LST, and which is not dependent on microfeature classifications. Finer resolution

546 satellites such as Sentinel-2 were not used in this study due to their lack of temperature data

547 meaning that they could not be used to calculate the TG model, but this may become possible in

548 future. Future work should also consider aerial remote sensing as an intermediate scale between

549 field spectrometry and satellite data; data from sensors mounted on both aeroplanes (Carless et al.,

550 2019; Räsänen et al., 2019) and Unmanned Aerial Vehicles (UAVs) (Beyer et al., 2019;

551 Scholefield et al., 2019) have begun to be used to assess peatland condition and vegetation

552 communities, and have the potential to be included in methods to estimate carbon fluxes.

\section{Conclusions}

554 In this study we have used a Temperature and Greenness (TG) model to estimate GPP from 555 remotely sensed data at small-scale and large-scale, and compared this to chamber and EC 556 measures of GPP.

557 The TG model successfully incorporates the factors which have the greatest relationship with GPP 558 at our study sites as shown by the exploratory factor analysis, and so produces an estimate of GPP 
559 that correlates with measured GPP at both small and large scales. Our results suggest that the

560 differences in GPP caused by peatland small-scale heterogeneity are temporally and spatially

561 inconsistent at our study sites, and that the TG model provides an average estimate. Future

562 iterations of the TG model should consider investigating the link between PAR and temperature

563 in more detail, and its effects on the model output, as it is hypothesised that this aspect of the model

564 may cause the underestimation of higher GPP values.

565 The EC results for GPP are larger than those from the chambers, possibly due to several reasons

566 including variation within the tower footprint, and the challenges of collar insertion and chamber

567 methodology. The TG model, however, shows good agreement with the chamber data at small-

568 scale and the EC data at large scale, suggesting that the model design is robust at all scales,

569 although dependent on the calibration data used. The authors can therefore recommend the use of

570 the TG model as a powerful tool for estimating peatland GPP across large areas, but reliable local

571 ground measurements should be used for calibration in order to give accurate values.

\section{Conflicts of Interest}

574 The authors declare no conflict of interest.

575 Acknowledgments

576 Thanks are due to the RSPB for their work on this project, and for site access and access to 577 facilities. Thanks also to the Environmental Research Institute (ERI) for their role in restoration 578 monitoring at the Forsinard Flows RSPB reserve. Thanks to Graham Hambley, Matthew Saunders, 579 Roxane Andersen and Neil Cowie for site set up and work coordination, and Rebecca McKenzie 580 and Peter Gilbert for site maintenance. Thanks to Kevin White and Suvarna Punalekar for 581 spectroradiometer training. Thanks to Alison Wilkinson for making 48 collars for the fieldwork.

582 We are very grateful for the help of our field assistants Ainoa Pravia, Jose van Paassen, Paul 583 Gaffney, Wouter Konings, Elias Costa, Zsofi Csillag, Valeria Mazzola, David and Parissa 584 Lumsden, and Joe Croft.

585 Funding 
586

587

588

589

590

591

592

593

594

595

596

597

598

599

600

601

602

603

604

605

606

607

608

609

610

611

612

613

614

615

616

617

618

619

620

621

622

623

624

625

Kirsten Lees was part funded by a studentship from The James Hutton Institute, and part funded by the Natural Environment Research Council (NERC) SCENARIO DTP (Grant number: NE/L002566/1). Tristan Quaife was funded by the NERC National Centre for Earth Observation (NCEO). Myroslava Khomik and Rebekka Artz were funded by The Scottish Government Strategic Research Programme 2016-2021. Jonathan Ritson was funded by the Engineering and Physical Sciences Research Council Twenty-65 project [Grant number EP/ N010124/1]. Much of the restoration work reported in this study was funded by EU LIFE, Peatland Action, HLF, and the RSPB

\section{References}

Arroyo-Mora, J. et al. (2018) 'Airborne Hyperspectral Evaluation of Maximum Gross Photosynthesis, Gravimetric Water Content, and CO2 Uptake Efficiency of the Mer Bleue Ombrotrophic Peatland', Remote Sensing. Multidisciplinary Digital Publishing Institute, 10(4), p. 565. doi: 10.3390/rs10040565.

Becker, T. et al. (2008) 'Do we miss the hot spots? - The use of very high resolution aerial photographs to quantify carbon fluxes in peatlands', Biogeosciences. European Geosciences Union, 5(5), pp. 1387-1393. doi: 10.5194/bg-5-1387-2008.

Belyea, L. R. and Clymo, R. S. (2001) 'Feedback control of the rate of peat formation', 268(1473), pp. 1315-1321. doi: 10.1098/rspb.2001.1665.

Beyer, F. et al. (2019) 'Multisensor data to derive peatland vegetation communities using a fixed-wing unmanned aerial vehicle', International Journal of Remote Sensing. Taylor and Francis Ltd., 40(24), pp. 9103-9125. doi: 10.1080/01431161.2019.1580825.

Campbell Scientific (2016) 'INSTRUCTION MANUAL EASYFLUX DL CR3000OP For CR3000 and Open-Path Eddy-Covariance System Revision: 3/18'. Available at: www.campbellsci.com. (Accessed: 9 July 2020).

Carless, D. et al. (2019) 'Mapping landscape-scale peatland degradation using airborne lidar and multispectral data', Landscape Ecology. Springer Netherlands, 34(6), pp. 1329-1345. doi: 10.1007/s10980-019-00844-5.

Chapman, S. J. et al. (2009) 'Carbon stocks in Scottish peatlands', Soil Use and Management. Wiley/Blackwell (10.1111), 25(2), pp. 105-112. doi: 10.1111/j.1475-2743.2009.00219.x.

Le Clec'h, S. et al. (2018) 'Mapping ecosystem services at the regional scale: the validity of an upscaling approach', International Journal of Geographical Information Science. Taylor \& Francis, 32(8), pp. 1593-1610. doi: 10.1080/13658816.2018.1445256.

Clement, R. J. et al. (2009) 'Improved trace gas flux estimation through IRGA sampling optimization', Agricultural and Forest Meteorology. Elsevier, 149(3-4), pp. 623-638. doi: 10.1016/J.AGRFORMET.2008.10.008.

Didan, K. (2015) 'MOD13Q1 V006 | LP DAAC :: NASA Land Data Products and Services'. NASA EOSDIS LP DAAC. doi: 10.5067/MODIS/MOD13Q1.006.

Dinsmore, K. J. et al. (2009) 'Spatial and temporal variability in CH4 and N2O fluxes from a Scottish ombrotrophic peatland: Implications for modelling and up-scaling', Soil Biology and Biochemistry, 41(6), pp. 1315-1323. doi: 10.1016/j.soilbio.2009.03.022. 
626

627

628

629

630

631

632

633

634

635

636

637

638

639

640

641

642

643

644

645

646

647

648

649

650

651

652

653

654

655

656

657

658

659

660

661

662

663

664

665

666

European Commission (2018) Regulation on land use, land use change and forestry in 2030 climate and energy framework adopted | Climate Action. Available at:

https://ec.europa.eu/clima/news/regulation-land-use-land-use-change-and-forestry-2030-climateand-energy-framework-adopted_en (Accessed: 9 July 2018).

Fratini, G. and Mauder, M. (2014) 'Towards a consistent eddy-covariance processing: an intercomparison of EddyPro and TK3', Atmospheric Measurement Techniques. Copernicus GmbH, 7(7), pp. 2273-2281. doi: 10.5194/amt-7-2273-2014.

Fu, D. et al. (2014) 'Estimating landscape net ecosystem exchange at high spatial-temporal resolution based on Landsat data, an improved upscaling model framework, and eddy covariance flux measurements', Remote Sensing of Environment. Elsevier, 141, pp. 90-104. doi: 10.1016/J.RSE.2013.10.029.

Gatis, N. et al. (2017) 'Evaluating MODIS vegetation products using digital images for quantifying local peatland $\mathrm{CO}_{2}$ gas fluxes', Remote Sensing in Ecology and Conservation. Edited by N. Pettorelli and M. Disney. Wiley-Blackwell, 3(4), pp. 217-231. doi:

$10.1002 / \mathrm{rse} 2.45$.

Gonzalez del Castillo, E. et al. (2018) 'Integrating proximal broad-band vegetation indices and carbon fluxes to model gross primary productivity in a tropical dry forest', Environmental Research Letters. IOP Publishing, 13(6), p. 065017. doi: 10.1088/1748-9326/aac3f0.

Griffis, T. J., Rouse, W. R. and Waddington, J. M. (2000) 'Scaling net ecosystem CO2 exchange from the community to landscape-level at a subarctic fen', Global Change Biology. John Wiley \& Sons, Ltd, 6(4), pp. 459-473. doi: 10.1046/j.1365-2486.2000.00330.x.

Hambley, G. (2016) The effect of forest-to-bog restoration on net ecosystem exchange in The Flow Country peatlands. University of St Andrews.

Hambley, G. et al. (2019) 'Net ecosystem exchange from two formerly afforested peatlands undergoing restoration in the Flow Country of Northern Scotland.', Mires and Peat, 23, pp. 114.

Hancock, M. H. et al. (2018) 'Vegetation response to restoration management of a blanket bog damaged by drainage and afforestation', Applied Vegetation Science. Edited by V. Vandvik. Wiley/Blackwell (10.1111), 21(2), pp. 167-178. doi: 10.1111/avsc.12367.

Heikkinen, J. E. P. et al. (2002) 'Carbon dioxide and methane dynamics in a sub-Arctic peatland in northern Finland', Polar Research. Routledge, 21(1), pp. 49-62. doi: 10.3402/polar.v21i1.6473.

Heinemeyer, A. et al. (2011) 'Soil respiration: implications of the plant-soil continuum and respiration chamber collar-insertion depth on measurement and modelling of soil CO2 efflux rates in three ecosystems', European Journal of Soil Science, 62(1), pp. 82-94. doi:

10.1111/j.1365-2389.2010.01331.x.

Helbig, M. et al. (2016) 'Addressing a systematic bias in carbon dioxide flux measurements with the EC150 and the IRGASON open-path gas analyzers', Agricultural and Forest Meteorology. Elsevier, 228-229, pp. 349-359. doi: 10.1016/J.AGRFORMET.2016.07.018.

IUCN (2016) A Secure Peatland Future A vision and strategy for the protection, restoration and sustainable management of UK peatlands. Available at: http://www.iucn-uk- 
667 peatlandprogramme.org/sites/www.iucn-uk-peatlandprogramme.org/files/CONSULTATION

668 DRAFT A Secure Peatland Future_WEB.pdf (Accessed: 9 July 2018).

669 JNCC (2011) Towards an assessment of the state of UK peatlands. Available at:

670 http://jncc.defra.gov.uk/pdf/jncc445_web.pdf (Accessed: 3 August 2018).

671 Kljun, N. et al. (2015) 'A simple two-dimensional parameterisation for Flux Footprint Prediction 672 (FFP)', Geosci. Model Dev, 8, pp. 3695-3713. doi: 10.5194/gmd-8-3695-2015.

673 Knox, S. H. et al. (2017) 'Using digital camera and Landsat imagery with eddy covariance data 674 to model gross primary production in restored wetlands', Agricultural and Forest Meteorology. 675 Elsevier, 237-238, pp. 233-245. doi: 10.1016/J.AGRFORMET.2017.02.020.

676 Kross, A., Seaquist, J. W. and Roulet, N. T. (2016) 'Light use efficiency of peatlands: Variability 677 and suitability for modeling ecosystem production', Remote Sensing of Environment. Elsevier, 678 183, pp. 239-249. doi: 10.1016/J.RSE.2016.05.004.

679 Laine, A. et al. (2006) 'Estimating net ecosystem exchange in a patterned ecosystem: Example 680 from blanket bog', Agricultural and Forest Meteorology. Elsevier, 138(1-4), pp. 231-243. doi: 681 10.1016/J.AGRFORMET.2006.05.005.

682 Laine, J. (2009) The intricate beauty of Sphagnum mosses : a Finnish guide for identification. 683 Department of Forest Ecology, University of Helsinki. Available at:

684 https://portals.iucn.org/library/node/29078 (Accessed: 13 August 2018).

685 Lees, K. J. et al. (2018) 'Potential for using remote sensing to estimate carbon fluxes across 686 northern peatlands - A review', Science of The Total Environment. Elsevier, 615, pp. 857-874. 687 doi: 10.1016/J.SCITOTENV.2017.09.103.

688 Lees, K.J., Quaife, T., et al. (2019) 'A model of gross primary productivity based on satellite 689 data suggests formerly afforested peatlands undergoing restoration regain full photosynthesis 690 capacity after five to ten years', Journal of Environmental Management. Academic Press, 246, 691 pp. 594-604. doi: 10.1016/J.JENVMAN.2019.03.040.

692 Lees, Kirsten J. et al. (2019) 'Changes in carbon flux and spectral reflectance of Sphagnum 693 mosses as a result of simulated drought', Ecohydrology. John Wiley \& Sons, Ltd. doi:

694 10.1002/eco.2123.

695 Lees, K.J., Clark, J. M., et al. (2019) 'Peatland vegetation: field and laboratory measurements of 696 carbon dioxide fluxes and spectral reflectance’. NERC Environmental Information Data Centre. 697 Available at: https://catalogue.ceh.ac.uk/documents/ab9f47f9-9faf-4403-a57e-25e31f581ed0.

698 Levy, P. E. and Gray, A. (2015) 'Greenhouse gas balance of a semi-natural peatbog in northern 699 Scotland’, Environmental Research Letters. IOP Publishing, 10(9), p. 094019. doi:

700 10.1088/1748-9326/10/9/094019.

701 LI-COR Biosciences (2017) ‘Eddy Covariance Processing Software (Version 7.0.6)’. Available 702 at: www.licor.com/EddyPro.

703 Lindsay, R. (2010) Peatbogs and Carbon: A critical synthesis. Available at:

704 http://ww2.rspb.org.uk/Images/Peatbogs_and_carbon_tcm9-255200.pdf (Accessed: 9 July 2018).

705 Lindsay, R. A. et al. (1988) The Flow Country - The peatlands of Caithness and Sutherland.

706 Available at: http://www.jncc.gov.uk/page-4281 (Accessed: 19 October 2018). 
Malhotra, A. et al. (2016) 'Ecohydrological feedbacks in peatlands: an empirical test of the relationship among vegetation, microtopography and water table', Ecohydrology. WileyBlackwell, 9(7), pp. 1346-1357. doi: 10.1002/eco.1731.

Met Office (2012) 'Met Office Integrated Data Archive System (MIDAS) Land and Marine Surface Stations Data (1853-current).' NCAS British Atmospheric Data Centre. Available at: NCAS British Atmospheric Data Centre.

Met Office (2018) Altnaharra SAWS climate information - Met Office. Available at: https://www.metoffice.gov.uk/public/weather/climate/gfkgdgj2j (Accessed: 9 July 2018).

Moore, D. J. P. et al. (2013) 'Persistent reduced ecosystem respiration after insect disturbance in high elevation forests', Ecology Letters. Edited by J. Penuelas. Wiley/Blackwell (10.1111), 16(6), pp. 731-737. doi: 10.1111/ele.12097.

Morton, P. A. and Heinemeyer, A. (2018) 'Vegetation matters: Correcting chamber carbon flux measurements using plant volumes', Science of The Total Environment. Elsevier, 639, pp. 769772. doi: 10.1016/J.SCITOTENV.2018.05.192.

Peichl, M. et al. (2018) 'Peatland vegetation composition and phenology drive the seasonal trajectory of maximum gross primary production', Scientific Reports. Nature Publishing Group, 8(1), p. 8012. doi: 10.1038/s41598-018-26147-4.

Phillips, M. E. (1954) 'Eriophorum Angustifolium Roth', The Journal of Ecology. British Ecological Society, 42(2), p. 612. doi: 10.2307/2256893.

R Core Team (2017) 'R: A language and environment for statistical computing.' Vienna, Austria.

Räsänen, A. et al. (2019) 'Comparing ultra-high spatial resolution remote-sensing methods in mapping peatland vegetation', Journal of Vegetation Science. Edited by D. Rocchini. WileyBlackwell, 30(5), pp. 1016-1026. doi: 10.1111/jvs.12769.

Santhana Vannan, S. K. et al. (2009) 'A Web-Based Subsetting Service for Regional Scale MODIS Land Products', IEEE Journal of Selected Topics in Applied Earth Observations and Remote Sensing, 2(4), pp. 319-328. doi: 10.1109/JSTARS.2009.2036585.

Scholefield, P. et al. (2019) 'Estimating habitat extent and carbon loss from an eroded northern blanket bog using UAV derived imagery and topography', Progress in Physical Geography: Earth and Environment. SAGE Publications Ltd, 43(2), pp. 282-298. doi: 10.1177/0309133319841300.

Sims, D. A. et al. (2008) 'A new model of gross primary productivity for North American ecosystems based solely on the enhanced vegetation index and land surface temperature from MODIS', Remote Sensing of Environment. Elsevier, 112(4), pp. 1633-1646. doi: 10.1016/J.RSE.2007.08.004.

Solangi, G. S., Siyal, A. A. and Siyal, P. (2019) 'Spatiotemporal Dynamics of Land Surface Temperature and Its Impact on the Vegetation', Civil Engineering Journal. Ital Publication, 5(8), pp. 1753-1763. doi: 10.28991/cej-2019-03091368.

Waddington, J. M. and Roulet, N. T. (1996) 'Atmosphere-wetland carbon exchanges: Scale dependency of $\mathrm{CO}_{2}$ and $\mathrm{CH}_{4}$ exchange on the developmental topography of a peatland', Global 
747 Biogeochemical Cycles. John Wiley \& Sons, Ltd, 10(2), pp. 233-245. doi: 10.1029/95GB03871.

748 Wan, Z., Hook, S. and Hulley, G. (2015) 'MOD11A2 MODIS/Terra Land Surface

749 Temperature/Emissivity 8-Day L3 Global 1km SIN Grid V006’. NASA EOSDIS LP DAAC.

750 doi: 10.5067/MODIS/MOD11A2.006.

751 Wang, G. et al. (2012) 'A three-dimensional gap filling method for large geophysical datasets:

752 Application to global satellite soil moisture observations', Environmental Modelling \& Software.

753 Elsevier, 30, pp. 139-142. doi: 10.1016/J.ENVSOFT.2011.10.015.

754 Wu, J. et al. (2011) 'Dealing with microtopography of an ombrotrophic bog for simulating 755 ecosystem-level CO2 exchanges', Ecological Modelling. Elsevier, 222(4), pp. 1038-1047. doi:

756 10.1016/J.ECOLMODEL.2010.07.015.

757 Wutzler, T. et al. (2018) 'Basic and extensible post-processing of eddy covariance flux data with 758 REddyProc’, Biogeosciences, 15(16), pp. 5015-5030. doi: 10.5194/bg-15-5015-2018.

759 Zhang, N. et al. (2007) 'Scaling up ecosystem productivity from patch to landscape: a case study 760 of Changbai Mountain Nature Reserve, China', Landscape Ecology. Springer Netherlands, 761 22(2), pp. 303-315. doi: 10.1007/s10980-006-9027-9. 